\title{
Naturaleza amena, naturaleza agreste en un estudio ecofeminista de La Isla de la Pasión (1989) de Laura Restrepo
}

\author{
Julia A. Kushigian \\ Connecticut College, Estados Unidos \\ jakus@conncoll.edu \\ https://orcid.org/0000-0002-9926-8466
}

Recibido: 10 de febrero 2018

Aceptado: 28 de mayo 2018

\section{Resumen:}

El acercamiento ecofeminista apunta hacia un enlace entre la naturaleza amena de la estética filosófica occidental y la naturaleza agreste de su faceta apocalíptica y monstruosa. Sirve de puente entre dos fuerzas opuestas para modelar y negociar la potencialidad representada por la política ecológica y la lucha por la justicia social. El presente estudio examina los costos de agresión, dominación y competencia al rescatar la historia mexicana en una narrativa alternativa, La Isla de la Pasión, escrita por la novelista colombiana Laura Restrepo. La novela investiga el poder de la naturaleza y la mujer de desmontar las jerarquías sociales y naturales y recrear unos sistemas más abiertos apoyándose en su lugar en sus valores inherentes. Se experimenta la transformación irónicamente en una isla casi desierta, abandonada por la patria mexicana pero codiciada por numerosos poderes multinacionales desde el comienzo del siglo XX. Es aquí en este microcosmos de la sociedad donde colindan los mundos de naturaleza amena y agreste para cosechar una naturaleza cómplice que ayuda en la lucha contra el desgaste de la tierra y la vida moral humana.

Palabras clave: autorrealización, ecocrítica, ecofeminismo, ecojusticia, espacio activista, desgaste, dualismos patriarcales, género, medioambiente, monstruo de la naturaleza, naturaleza agreste, naturaleza amena, naturaleza cómplice, potencialidad, raza, supervivencia.

\section{"Idyllic Nature/Savage Nature in an Ecofeminist Study of} The Isle of Passion (1989) by Laura Restrepo"

\section{(C) $(\triangle 0)$}

La Revista Estudios es editada por la Universidad de Costa Rica y se distribuye bajo una Licencia Creative Commons Atribución-NoComercial-CompartirIgual 3.0 Costa Rica. Para más información envíe un mensaje a 
Especial: Naturaleza amena y naturaleza agreste en las letras hispánicas

\section{Abstract:}

The ecofeminist approach explores a link between an idyllic nature of the western philosophical aesthetic and an aggressive nature inherent in its apocalyptic and monstrous side. This approach serves as a bridge between two competing forces to model and negotiate the potentiality represented by political ecology and the quest for social justice. This study examines the costs of aggression, domination and competition by reclaiming a story from Mexican history and reformulating it in the alternative narrative, The Isle of Passion, written by Colombian novelist Laura Restrepo. The novel discovers both the power of nature and women to dismantle social and natural hierarchies and recreate more open systems relying, in their place, on their inherent values. This transformation is ironically achieved on an almost deserted island, which was ignored by the Mexican government but desired by numerous multinational powers since the beginning of the twentieth century. It is here in this microcosm of society where the two worlds of savage and idyllic nature collide to yield a figure of nature as partner and collaborator that aides in the battle against the decaying of the earth and human moral life.

Key words: Activist space, collaborative nature, decay, ecocriticism, ecofeminism, ecojustice, environment, gender, idyllic nature, monster of nature, patriarchal dualisms, potentiality, race, savage nature, self-realization, social class, survival.

Laura Restrepo es una de las novelistas latinoamericanas más innovadoras y relevantes, que incorpora temas de marco histórico, cultural, político, feminista y ecológico, recalcando su honda preocupación por la vida en América. Mucha de su producción literaria es influida por sus intereses políticos y periodísticos, dos campos a que se dedicaba la escritora colombiana antes de emprender una carrera literaria de ficción. La Isla de la Pasión se escribe en el exilio en México como homenaje a su país adoptivo, arrojando luz sobre los temas concretos del exilio y del desplazamiento que afectan tanto la historia de México como la de su país natal y en mayor escala, la actualidad latinoamericana. La autora detalla con un ojo crítico la perspectiva ajena que permite, como afirma el filólogo Eric Auerbach, distanciarse de lo "real" o conocido, trascender lo inmediato, y apreciar su propia cultura en relación a otras. Lo mimético se convierte en lo nuevo, y lo

\section{(c) (7) (-)}

La Revista Estudios es editada por la Universidad de Costa Rica y se distribuye bajo una Licencia Creative Commons Atribución-NoComercial-CompartirIgual 3.0 Costa Rica. Para más información envíe un mensaje a 
Especial: Naturaleza amena y naturaleza agreste en las letras hispánicas nuevo para la autora se ahonda en una preocupación naciente por la vida humana en relación con la naturaleza. ${ }^{i}$ En La Isla de la Pasión conviven ejemplos de la naturaleza agreste (guano, mantarrayas, monstruos de la naturaleza, agua salada, arrecifes de coral y huracanes) y la naturaleza amena (brisas, agua dulce, palmeros, huerta, vida humana y fauna). La novela se sitúa en una tradición de ecocrítica de los años 90 que reevalúa el papel de la naturaleza desde la tradición oral precolombina, las crónicas latinoamericanas, y los estudios científicos de Alexander Von Humboldt hasta la literatura del siglo XXI, explayando los múltiples roles, funciones y representaciones de la naturaleza en la literatura latinoamericana. ii De ahí que se destaca La isla de la pasión por su relación íntima con una naturaleza colaboradora que fusiona lo ameno y agreste. Se presta a su estudio el análisis ecofeminista porque combina fundamentalmente los acercamientos ecocrítico y feminista en un rechazo de la degradación de la mujer y la naturaleza. En esencia, logra plantear y combatir culturalmente aun en una isla desierta los costos de agresión, dominación y competencia en un microcosmos de la sociedad latinoamericana.

La mayoría de las lecturas críticas de La isla de la pasión hasta el presente exploran la novela retóricamente por su hibridez (Vignolo, Maíz-Peña), económicamente por temas de exilio, inmigración y mercados internacionales (Carreño Pedraza), socialmente por la norma poscolonial que desvalora la subjetividad colonial (Melis 2005), o racialmente por sus figuras marginalizadas, negras o grotescas (Hughes Davis). Existe también el estudio feminista de la novela evidente en su proyecto de varios géneros culturales para superar la centralidad de la experiencia varonil: anotaciones de bitácora, un poema, un dossier de expedientes, tarjetas de invitación, una tarjeta postal, textos históricos y militares, diarios históricos y de marina, entrevistas, epitafios y un acta de matrimonio (Melis 2011). Como la producción cultural femenina siempre se ha manifestado a base de posiciones conflictivas e inestables, el público lector logra 
Especial: Naturaleza amena y naturaleza agreste en las letras hispánicas

apreciar su voz narrativa innovadora, en contraste con los editores que primeramente rechazaron el manuscrito de la autora (entrevista con Jaime Manrique). En el enlace entre la ecología y el feminismo, donde el ecofeminismo no sólo presenta narrativas alternativas sino también posibilidades para el cambio (Cambell xii), se privilegia la relación inextricable entre mujer y naturaleza al rechazar los dualismos patriarcales de la filosofía occidental. El presente estudio enfoca la lente crítica en el ecofeminismo porque indaga en la justicia social experimentada en la relación fluida entre raza, sexualidad y clase social como entes biológicos y naturales.iii Se distingue así de las muchas ramas feministas porque su lucha por la justicia social se disputa en el espacio de relación entre la vida humana y la naturaleza. Es decir, se filtra por la ecojusticia, donde preservar la naturaleza es hacer justicia a los más pobres y el resto de las criaturas vivientes (Gevara). Las preguntas fundacionales de la socióloga ecofeminista, Alicia Puleo, ¿qué relación mantenemos con la naturaleza, qué lugar tenemos las mujeres en la sociedad, y qué relación existe entre los movimientos feministas y ecologistas?, orientan nuestra lectura de la novela a la confluencia de cuestiones humanas y naturales. Con el ecofeminismo, se aproxima a una diversidad innovadora de narrativas alternativas y una crítica más fuerte de ideologías opresivas.

Irónicamente, el ímpetu del argumento de La isla de la pasión es la historia del capitán Ramón Arnaud, un soldado joven de ascendencia francesa, encarcelado por deserción. Tiene muy poca experiencia militar cuando es mandado en 1908 a Clipperton/Isla de la Pasión por el ejército de Porfirio Díaz como forma de borrar su pecado de deserción. Acompañado por su esposa Alicia, once soldados y sus familias, intentan todos asegurar la defensa de una isla realmente ignorada por la comunidad mexicana pero codiciada por los franceses, los norteamericanos y los ingleses. La Isla de la Pasión sufre de una crisis de identidad que heredará a sus habitantes. Es un atolón perdido, reconocida por su nombre en español dado por el explorador Fernando de Magallanes, y su nombre

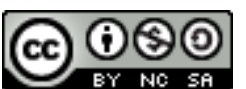

La Revista Estudios es editada por la Universidad de Costa Rica y se distribuye bajo una Licencia Creative Commons Atribución-NoComercial-CompartirIgual 3.0 Costa Rica. Para más información envíe un mensaje a 
Especial: Naturaleza amena y naturaleza agreste en las letras hispánicas en inglés, Clipperton, por el corsario inglés John Clipperton, quien llegó allí por primera vez en 1705. Similar a la crisis de identidad que sufre Las Malvinas en Argentina, Clipperton es más conocida por su ubicación marítima que por alguna evidencia de su valor o carácter nacional: "Quien imagine un mapamundi puede ubicarla en el punto de cruce de un eje que bajara de Acapulco hacia el sur y otro que partiera de San José de Costa Rica hacia el oeste, y comprobar que está en la misma posición con respeto a la línea ecuatorial que Cartagena y Maracaibo. Eso es lo que se sabe, y sin embargo algunas cartas de navegación la relegan a la incertidumbre al marcarla con la sigla "D.E.", Doubtful Existence, existencia dudosa" (14-15).

Disputada por cuatro naciones, Clipperton y sus habitantes sobreviven las guerras de Independencia, la Revolución Mexicana y la Primera Guerra Mundial, preparándose para la defensa de un asalto que nunca llega. Viéndose todos abandonados por su patria que promete llevarles refuerzos y una carga de supervisiones cada tres meses que se extiende cada vez más sin cumplir, el amor por la patria se convierte en un instinto de sobrevivir: la búsqueda de comida, la protección del sol, de enfermedades, miles de cangrejos, mantarrayas, tiburones, los arrecifes de coral, la locura, el hambre, la violación y el olvido. Laura Restrepo logra cumplir la función que la historia no ha captado y eso es que los personajes históricos no se queden en el olvido, que tenga sentido dentro de la historia de México y ayude a comprender su identidad y posición frente las potencias coloniales e imperialistas (Osorio 98). En particular, la posición de la mujer frente la sociedad patriarcal se esclarece en su cuestionar de los papeles femeninos relacionados a la tierra, labor y capital, dada la economía de encrucijada marítima y política ecológica de la isla. Es evidente el desafío de los papeles en el choque de razas, clases sociales, y géneros experimentado paradójicamente en una isla desolada y lejos de la civilización. Emprende una odisea mitológica y humana con

\section{(c) (i) (2)}

La Revista Estudios es editada por la Universidad de Costa Rica y se distribuye bajo una Licencia Creative Commons Atribución-NoComercial-CompartirIgual 3.0 Costa Rica. Para más información envíe un mensaje a 
Especial: Naturaleza amena y naturaleza agreste en las letras hispánicas

la naturaleza amena y la naturaleza agreste para llegar a la naturaleza cómplice en una sociedad de su propia creación. ${ }^{\text {iv }}$

La isla de la pasión anuncia el primer indicio de la rebeldía contra las normas sociales con el enfrentamiento de los roles sexuales antes de casarse Alicia con Ramón en México. La madre de Alicia les da consejos a sus tres hijas sobre el rol de la mujer. Les avisa de que en caso de encontrarse en una temible situación de violación, es mejor pegarse un tiro antes de permitir que las deshonren, revelando el implícito valor inferior de la mujer tanto moral como socialmente. Las hijas, incluyendo a Alicia, contestan a su madre que sería mejor pegarle el tiro al hombre dando evidencia explícita feminista intercalada por la autora y también un toque ecofeminista en subir el rango femenino para emparejar con el poder del hombre en la condición natural. La solución de las tres hermanas jóvenes le servirá de timón a Alicia para vivir su vida y enfrentar al torturador y monstruo de la naturaleza que abusará a las mujeres de la isla en su futuro lejano. Pero al principio, Alicia pasa los primeros años de su matrimonio en Clipperton como si estuviera en el exilio, lejos de los papeles predestinados para la mujer de sociedad a comienzos del siglo XX con sus constricciones victorianas de la naturaleza sexual femenina y de su poder financiero.

La protagonista central de la novela es la esposa del capitán Arnaud, Alicia Rovira de Arnaud, agente de su autorrealización ecofeminista hacia la potencialidad. En Clipperton, "la adolescente Alicia encontró el lugar romántico y mágico, tal como lo había soñado, y se enamoró de sus atardeceres y de su paz" (16). En principio la isla es percibida como un paraíso de la naturaleza amena para Alicia y sus cuatro hijos, que nunca conocieron otra vida y fueron felices jugando todo el día o tomando clases con Alicia y los demás niños de la isla. Mientras los adultos recuerdan a Clipperton como un calvario, los niños recuerdan una vida alegre y sin prejuicios jugando sueltos bajo el sol hasta acabar "renegridos de tanto aguantar sol" (21), jugando con los barcos tallados por el

\section{(c) (i)(2)}

La Revista Estudios es editada por la Universidad de Costa Rica y se distribuye bajo una Licencia Creative Commons Atribución-NoComercial-CompartirIgual 3.0 Costa Rica. Para más información envíe un mensaje a 
Especial: Naturaleza amena y naturaleza agreste en las letras hispánicas capitán Arnaud, las peleas de cangrejos, el mar y los pájaros bobos. En general, no conocen el sufrimiento, pero la oración de tesis que abre la novela pronostica como una aporía al conjurar el microcosmos social de la vida petrificada que les espera: "Una muñeca abandonada entre las rocas desde hace docenas de años. Se le borraron las pestañas y el color de las mejillas y los animales mordisquearon su piel de porcelana. Ella observa, lela, con las cuencas vacías de sus ojos y todo lo registra en su cráneo carcomido por la sal" (13). En esencia, esta observación por parte de la autora de pequeños detalles sintetiza momentos históricos significativos y re-dramatiza la gravedad anticipada de los hechos por venir (MaízPeña), pero también señala el poder de la supervivencia. La existencia de la muñeca que persiste aún "docenas de años" después de la residencia de las familias en la Isla de la Pasión, recalca la potencialidad de la protagonista Alicia.

En la isla Alicia siente una gran libertad y deseo de hacerle a su marido amante y amigo de una relación entrañable, donde le compadecerá su lógica, inteligencia, y fuerza natural. Desde la disposición de los cuartos, muebles y artefactos de la casa en la isla hasta la huerta y el compartir de las mismas historias e impresiones diarias en la oscuridad de la noche larga, el hogar y la isla en vez de simbolizar una prisión para la mujer representan un espacio activista, cediéndole el espacio para ser agente de su propia vida. Mientras el Capitán Ramón Arnaud espera soluciones antropocéntricas desde afuera - las órdenes militares, el suplir de lo necesario para sobrevivir, alguna señal de uno de los gobiernos mexicanos que abandonaran o siguieran su carga de defensa - su esposa, Alicia, hace, ordena, gasta energía, inventa, intenta y soluciona en ritmo con la naturaleza. Aun cuando Ramón se empeña en desvalorizar el afán de su mujer señalando su tarea de "contrasentido" que desmitifica es su mente la densidad del calor y rompe la quietud natural de los demás, Alicia se pone manos a la obra y logra cumplir con cargos inverosímiles. En efecto, incluso el acto de dar a luz a su primer hijo de cuatro en total, cobra más fuerza en una isla hostil

\section{(C) $(00$}

La Revista Estudios es editada por la Universidad de Costa Rica y se distribuye bajo una Licencia Creative Commons Atribución-NoComercial-CompartirIgual 3.0 Costa Rica. Para más información envíe un mensaje a 
Especial: Naturaleza amena y naturaleza agreste en las letras hispánicas porque lejos de una simple asociación de la mujer con su poder reproductivo en la naturaleza, Alicia redobla el esfuerzo para convertirse en símbolo de la voluntad del poder a que se ceñirá para sobrevivir en el futuro.

Sabiendo que poblar es fundar una sociedad nueva, "Alicia dio rienda suelta a un impulso más telúrico que humano que desató en su interior y que copó todos sus sentidos. El dolor, aunque en su punto máximo, pasó a segundo plano, convirtiéndose en una sensación débil, sin importancia, ante la potencia del esfuerzo. También el miedo y la incertidumbre de las horas anteriores quedaron borrados ante una gloriosa voluntad de poder, ante una fe ciega en su propia fuerza, que brotaba monumental" (122). Los desafíos naturales como el huracán y el diluvio que arrastran la isla en 1914 le desconciertan a Ramón y le hacen criticar a Alicia con "tú siempre haciendo disparates en los momentos más inoportunos" (157). Pero el disparate a que se refiere es arrastrar un baúl con todas sus pertenencias y tesoros personales al galpón de guano donde se refugian en el huracán. Para Alicia precisamente este acto le ofrece una plataforma más para imponer su orden, tratar a los heridos e imaginar su propia historia y vida que incluyan a todos. Aquí el ecofeminismo es una forma de estar presentes en la elaboración de un modelo para el futuro que realmente circunscriba a todos, mujeres y hombres, niñas y niños, ancianas y ancianos. Recalca los estereotipos y las estructuras patriarcales que están grabados en la conciencia general para reemplazarlos con normas relacionales de supervivencia y convivencia importantes incluso para el siglo XXI.

La valentía de Alicia es contagiosa y se comparte en un doble sentido con las mujeres de raza como Tirsa (174) y Altagracia (198) para curar y seguir viviendo. La novela narra sobre todo las vidas de las mujeres dada la desaparición de los varones por enfermedades, desastres marítimos, ataques de mantarrayas y actos violentos. Lejos de la civilización, las mujeres y la naturaleza enfrentan igual el desprecio de la jerarquía social patriarcal. La foto de sepia sacada unos días

La Revista Estudios es editada por la Universidad de Costa Rica y se distribuye bajo una Licencia Creative Commons Atribución-NoComercial-CompartirIgual 3.0 Costa Rica. Para más información envíe un mensaje a 
Especial: Naturaleza amena y naturaleza agreste en las letras hispánicas antes de su boda con su "piel de porcelana de su cara de muñeca," (38) la asocia con la muñeca de la tesis de oración y presagia la condición paralela de Alicia y su isla lavadas las dos por el sol y el guano, batidas como la muñeca por las olas, los pájaros, los cangrejos, y otras fuerzas de la naturaleza. Pero convertida más tarde en gobernadora después de la muerte de su esposo, Alicia encarna la confluencia de normas sexuales, clases sociales y razas dada su preocupación por la relación entre el bienestar natural y la equidad de todos incluyendo a los pobres, maltratados y marginalizados de la isla.

La narración de la naturaleza cómplice es la autorrealización de Alicia, quien, empieza el proceso de hacerse después de la muerte de los hombres: "Aquí se murieron los hombres -dijo-. Pero nosotras seguimos vivas. Están vivos los niños, y hay que alimentarlos. No va a ser fácil. Hay que trabajar duro, así que se acabó el duelo. Basta de llorar por los maridos, porque tenemos que cuidar a los hijos" (263). En realidad, ésta es una llamada ecofeminista a la acción nacida de un movimiento práctico para el cambio social y la relación con la naturaleza cómplice. Se vincula con los esfuerzos de las mujeres de mantenerse a sí mismas, y de proteger a sus familias y sus comunidades (Gaard y Murphy 2). Al destacar sus sistemas simbólicos, es posible concluir que en Alicia se radique la esencia de todas las ramas ecofeministas económicas, constructivistas, espirituales, biológicas, y sociales. La autoridad moral, el poder activista, la fabricación de ropa y auxiliares médicos de la nada, el cultivo de comida, el cuido sobrehumano de los niños y de los marginalizados necesitados, y la defensa de la isla son compartidos todos por la protagonista Alicia. La administración política de la isla después de la muerte del capitán Arnaud, su esposo, y su administración medioambiental caen sobre los hombros de Alicia, aunque la Historia desfavorezca a la mujer mientras reclame la justicia medioambiental.

Es de sobre conocido que el movimiento de justicia medioambiental hoy en día está encabezado más que nunca por mujeres y una presencia cada vez más 
Especial: Naturaleza amena y naturaleza agreste en las letras hispánicas

fuerte de minorías (Buell 33) y por eso el ecofeminismo es una herramienta sumamente útil en el análisis de la literatura (Devries 15). Tratando de la invisibilidad de la mujer en posiciones de liderazgo, es importante que Alicia predestine, como precursora, una nueva realidad con la ayuda de la naturaleza cómplice, llevando a todos a una sociedad menos cerrada y tradicional. La novela plantea su odisea de una forma directa y escueta, reflejando así la realidad de la isla: "...la narración es muy eficaz, ya que el lector se vuelve testigo de un proceso verosímilmente vital en el cual deseos, energías, valores y sueños humanos se ven anulados por una imposibilidad geográfica, histórica y política." A las imposibilidades citadas se les añade la imposibilidad medioambiental de la naturaleza. La diversidad medioambiental incluye la diversidad racial, de clase social y de género porque busca borrar diferencias, pero choca contra las normas tradicionales de la jerarquía social. Por ejemplo, negocia los límites de la naturaleza cómplice cuando Alicia se hace líder y gobernadora de la isla y el esclavo Victoriano rehúsa cumplir su cargo laboral o social. Al final, Victoriano se tira hacia la imagen del monstruo de la naturaleza y tiene que ser extinguido.

Después del huracán, la soledad, la muerte de los hombres y la conquista del escorbuto, la naturaleza agreste se personifica en el esclavo Victoriano. La figura de Victoriano Álvarez es sumamente complicada porque él es odiado por su raza y hecho el chivo expiatorio durante su juventud. También, es símbolo de contagiosas enfermedades viles y la violación de mujeres en la isla de Clipperton: "el negro era un despojo humano. Apestaba, supuraba y no podía levantarse de la hamaca ni para aliviar sus necesidades...Victoriano la agarró [a Alicia] de una mano y trató de retenerla pero ella se zafó y salió en estampida, como si la hubiera tocado Lucifer en persona" (237). En general, se asocia la naturaleza grotesca con el color negro en la novela: la negrura de las encías significa la muerte incipiente a causa del escorbuto, una mantarraya negra ataca y mata a Ramón y el teniente Cardona, y el esclavo Victoriano se auto-declara gobernador 
Especial: Naturaleza amena y naturaleza agreste en las letras hispánicas de la isla después de la muerte de los demás hombres, recogiendo como despojo a las mujeres. Pensando que han evitado el peligro de contaminarse por Victoriano por su muerte del escorbuto, las mujeres se creen libres del monstruo una vez por todas, pero se "resucita" más violento que nunca, siendo contra todo sentido y naturaleza el único varón vivo.

Victoriano representa el desgaste de la tierra y de "la raza de color" en La isla de la pasión ocasionado por las empresas multinacionales y la sociedad patriarcal, similar al desgaste experimentado en la novela Mamita Yunai (1941) de Costa Rica. ${ }^{\text {vi }}$ En la novela de Restrepo se repite el tema del desgaste de recursos naturales por las grandes empresas globales británicas y estadounidenses que quieren aprovecharse de la abundancia natural de guano y salitre. Igualmente abandonan sus construcciones y sus representantes al cancelar sus recursos o a la menor indicación de contratiempos políticos y económicos. Como Alicia no quiere aceptar el papel de Robinson Crusoe del náufrago o marrón abandonado a la temperie, opta, en su lugar, por el papel de defensora de la naturaleza cómplice que apoye a la diversidad para enriquecer la sociedad y rechazar los monstruos de la naturaleza como Victoriano Álvarez que buscan destruirla. Al principio están felices de verlo con vida, pero al final lo aceptan como un desafío más: "Al fin quedamos nosotras y tú - le dijo Alicia -. No es raro, las mujeres y los negros somos las dos razas más resistentes del planeta" (294). Su creencia en la potencialidad de la biodiversidad la prepara para la respuesta de Victoriano, con clara intención maléfica para insultarlas y bajarlas irónicamente a su nivel con la contaminación con la raza de color: "-Y ustedes se volvieron negras" (294). Aunque el lenguaje no incorpora la cultura, y por eso no presenta impedimentos a la comunicación del sentido, la noción de la diferencia, de una coyuntura indescifrable entre realidades culturales sí es diligentemente construida en el texto literario (Tiffany, Ashcroft, y Griffiths 56). La noción de la diferencia está tan contradictoria pero diligentemente construida en La isla de la pasión como si nos

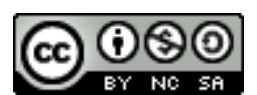

La Revista Estudios es editada por la Universidad de Costa Rica y se distribuye bajo una Licencia Creative Commons Atribución-NoComercial-CompartirIgual 3.0 Costa Rica. Para más información envíe un mensaje a 
Especial: Naturaleza amena y naturaleza agreste en las letras hispánicas quisiera recomendar el lema "las vidas negras importan" por un lado, y nos avisara del apocalipsis creado por la negritud, por otro, para dejar abierta su interpretación. Termina la entrevista Alicia con Victoriano: “-Pues sí, mira no más, sí estamos renegras, como tú. El sol nos puso a todos iguales" (294).

Al querer ser magnánima, igualitaria y creer en la potencialidad humana, Alicia de su escasez le regala a Victoriano sábanas, una cuchara, y otras cosas que pide prestadas, pero a fin de cuentas no logra disuadir sus impulsos naturales a tomar y matar por imperioso. Con la evidencia del asesinato de Benita que lleva a su choza como esclava, tanto Alicia como Tirsa, las dos al punto de dar a luz unos meses después de la muerte repentina de sus esposos, deciden que ha llegado la hora de enfrentar a Victoriano y su naturaleza demencial. Alicia se le acerca mientras pesca y trata de convencerle de un cambio de la jerarquía social y natural que ordene la justicia social. Quiere que él acepte un trastorno social y político al plantearle matrimonio entre los dos para que él salga de gobernador "legítimo" de la isla: "eres un tirano y nos dominas a golpes, pero no tienes autoridad sobre nadie. Yo en cambio, sí soy gobernadora, porque a mi marido le dio ese título Porfirio Díaz" (320). Victoriano lo piensa, pero intenta aclarar: “¿El que se casa con gobernadora se vuelve gobernador? [...] Eso me gusta, ser gobernador legítimo, como mi abuelo" (320). La atracción de la legitimidad que va en contra de la jerarquía social le ciega la vista queriendo saber si los hijos de Alicia y el capitán Arnaud lo aceptarían como padre, y mientras lo rumia, Tirsa intenta matarlo con un mazo. Al fallar el intento, Alicia no ve más remedio que hundirle los dientes en el brazo y con la distracción Tirsa descarga un mazazo en el centro de la cabeza y le clava un arpón en el pecho para rematarlo. Es la única solución que ven porque aun cuando se les acerca el cañonero norteamericano Yorktown, no creen que Victoriano les deje a las mujeres y los niños con vida para un rescate. Están convencidas de su promesa de naturaleza agreste de asesinarlos a todos para deshacerse de la evidencia de vida ajena ante la 
Especial: Naturaleza amena y naturaleza agreste en las letras hispánicas posibilidad de un rescate. En vez de apropiar y dominar la naturaleza como herramienta para satisfacer sus necesidades humanas, la gobernadora Alicia convive con la naturaleza siguiendo su selección más apta para asegurar la supervivencia.

En conclusión, el impulso de La isla de la pasión es de incorporar una historia mexicana poco difundida por el pueblo mexicano que registre un homenaje a su país adoptivo y que dé ocasión para explorar la identidad latinoamericana por la lupa de raza, género y clase social. A ese impulso creador se añade los impulsos feministas, ecofeministas y poscoloniales de crítica cultural de las instituciones restrictivas endeudadas a las jerarquías patriarcales y la globalización y sus empresas multinacionales. El desliz de reportero a novelista afirma en Restrepo una estrategia activista que no se mengua con el exilio, "Hay como una necesidad de ir más allá de lo evidente. O sea, partir de lo evidente, pero con la convicción de que estás viendo apenas la superficie, y que esa superficie está ya sujeta a interpretaciones previas, que no son realmente las que emanan de la realidad. Y una necesidad de dedicarse con más tiempo, con más tesón, con más sucesión. Ese timing te lo da más la literatura...la ficción entendida como la posibilidad de ampliar y complementar" (citado en Melis, 2005: 117). El ímpetu periodístico de investigación y testigo influye en las obras de Restrepo en general y desarraiga para sacar a luz la explotación de los que han sido marginalizados por su raza, género, y clase social, como el efecto pernicioso de los intereses multinacionales sobre las comunidades locales. Distanciándose de las narrativas de supervivencia como Robinson Crusoe o de la novela latinoamericana de la tierra, las héroes de La Isla de la Pasión son mujeres de razas y clases sociales dispares, esposas de soldados y soldaderas, pero con unas cualidades en común como su inteligencia, capacidad, instinto de perseverancia, y supervivencia social para imponerse y triunfar (Averis 253). Contadas las circunstancias apocalípticas desde fragmentos de archivos históricos y militares, recortes de periódicos, diarios

\section{(c) (i) (2)}

La Revista Estudios es editada por la Universidad de Costa Rica y se distribuye bajo una Licencia Creative Commons Atribución-NoComercial-CompartirIgual 3.0 Costa Rica. Para más información envíe un mensaje a 
Especial: Naturaleza amena y naturaleza agreste en las letras hispánicas

y entrevistas, Laura Restrepo va llenando los huecos con unas voces narrativas e imaginadas ecofeministas mezcladas con la teoría poscolonial donde, según Walter Mignolo, la escritura de la historia tiene otra lógica y otro lenguaje que contribuye a la descolonización del conocimiento. vii La isla de la pasión es una metáfora del exilio y la soberanía, con un esfuerzo de legitimar la isla nación tanto por el respeto al poder de la supervivencia, la biodiversidad, las razas y la mujer, como por la naturaleza misma cómplice.

\section{REFERENCIAS}

André, María Claudia. "Deseo, represión y locura en Delirio de Laura Restrepo." Juana Alcira Arancibia, editor. La mujer en la literatura del mundo hispánico. Buenos Aires: Instituto literario y cultural hispánico, 2005: 255-270.

Averis, Kate. "Laura Restrepo." Will H. Corral, Juan E. De Castro, Nicholas Birns. The Contemporary Spanish-American Novel: Boloño and After. New York: Bloomsbury Academic 2013.

Ashcroft, Bill, Gareth Griffiths y Helen Tiffin. The Empire Writes Back. Theory and Practice in Post-colonial Literatures. London: Routledge, 2003.

Buell, Lawrence. Writing for an Endangered World. Literature, Culture, and Environment in the U.S. and Beyond. Belknap Press, Harvard UP, Cambridge, MA, 2001.

Campbell, Andrea, editora. New Directions in Ecofeminist Literary Criticism. Newcastle, UK: Cambridge Scholars Publishing, 2008.

\section{(c) (i) (9) (2)}

La Revista Estudios es editada por la Universidad de Costa Rica y se distribuye bajo una Licencia Creative Commons Atribución-NoComercial-CompartirIgual 3.0 Costa Rica. Para más información envíe un mensaje a revistaestudios.eeg@ucr.ac.cr. 
Especial: Naturaleza amena y naturaleza agreste en las letras hispánicas

Carreño Pedraza, Elisa Alejandra. "La isla de la pasión de Laura Restrepo" Revista de Literatura Contemporánea Mexicana 14, 2007: 123-124.

DeVries, Scott. A History of Ecology and Environmentalism in Spanish American Literature. Lewisburg, PA: Bucknell UP, 2013.

Gaard, Greta y Patrick D. Murphy, editores. Ecofeminist Literary Criticism: Theory, Interpretation, Pedagogy. Chicago: University of Illinois Press, 1998.

Gebara, Ivone. "Ivone Gebara: Jerarquía de la iglesia, obstáculo para el empoderamiento femenino." http://www.webislam.com/articulos/37256ivone gebara-jerarquia.

Hughes Davis, Lloyd. "Laura Restrepo." Lloyd Hughes Davis y Brígida Pastor, editors. A Companion to Latin American Women Writers, 2012: 197-211.

Melis, Daniela. "Una entrevista con Laura Restrepo" Chasqui 34 (1) 2005: 114129.

---. "Creation and (Re)presentation of Historical Discourse in Isle of Passion by Laura Restrepo." Studies in 20th \& 21st Century Literature, Vol. 35, 2011: 250267.

Merchant, Carolyn. The Death of Nature. Women, Ecology and the Scientific Revolution. New York: Harper Collins, 1983.

Mignolo, Walter D. Local Histories/Global Designs. Coloniality, Subaltern Knowledges, and Border Thinking. Princeton: Princeton UP, 2000.

\section{(C) $(00$}

La Revista Estudios es editada por la Universidad de Costa Rica y se distribuye bajo una Licencia Creative Commons Atribución-NoComercial-CompartirIgual 3.0 Costa Rica. Para más información envíe un mensaje a revistaestudios.eeg@ucr.ac.cr. 
Especial: Naturaleza amena y naturaleza agreste en las letras hispánicas

Osorio, José Jesús. "Relaciones ambiguas: periodismo y literature en La isla de la pasión." Elvira Sánchez-Blake y Julie Lirot, editoras. El universo literario de Laura Restrepo. Bogotá: Taurus/Alfaguara, 2007: 93-108.

Puleo, Alicia. "Existe un ecofeminismo para la igualdad en el futuro modelo de desarrollo." http://www.mujeresenred.net/spip.php?article1249.

Restrepo, Laura. La Isla de la Pasión. New York: Rayo/Harper Collins, 2005.

---. con Jaime Manrique, "Entrevista con Laura Restrepo." Elvira Sánchez-Blake y Julie Lirot, editoras. El universo literario de Laura Restrepo. Bogotá: Taurus/Alfaguara, 2007: 353-367.

Sánchez-Blake, Elvira y Julie Lirot, editoras. El universo literario de Laura Restrepo. Bogotá: Taurus/Alfaguara, 2007.

Warren, Karen J. "A Feminist Philosophical Perspective on Ecofeminist Spiritualities." Carol J. Adams, editora. Ecofeminism and the Sacred. New York: Continuum, 1993.

---. Ecofeminist Philosophy. A Western Perspective on What It Is and Why It Matters. New York: Rowman \& Littlefield, 2000.

Williams, Raymond L. "Nature in the Twentieth-Century Latin American Novel (1900-1967) and in Cien años de soledad of García Márquez." Adrian Taylor Kane, editor. The Natural World in Latin American Literatures: Ecocritical Essays on Twentieth Century Writings. Jefferson, NC: MacFarland \& Co. Publishers, 2010: 66-88.

\footnotetext{
' Restrepo aclara en su entrevista con Jaime Manrique, "El primer año de mi exilio en México fue un tiempo de aislamiento y de añoranzas, de soñar a todas horas con el momento en que me fuera 
Especial: Naturaleza amena y naturaleza agreste en las letras hispánicas

dada la posibilidad de regresar a Colombia, de andar pendiente de cualquier noticia o periódico viejo que llegara de mi tierra y de mi gente, de andar rodeada de otros exiliados con quienes compartía destino común. Un buen día amanecí cansada de todo eso: me di cuenta de que tenía a mi alcance ese país maravilloso que es México y que me lo estaba perdiendo por andar con la cabeza y el corazón embebidos en Colombia. Entonces empecé a buscar una historia local que me permitiera escribir un nuevo libro [...] Aquello no sólo me resultaba apasionante, sino que además - y supongo que eso fue lo fundamental - se me aparecía como la posibilidad de hablar en términos metafóricos de mi propia situación en ese momento: de mi confinamiento en esa muy particular isla que es el exilio político, con su extraña lucha por la supervivencia y la estrecha convivencia forzada con sus peculiares náufragos" 360-361.

ii Sobre la ecocrítica como fenómeno, Raymond L. Williams destaca los estudios pioneros del teorista Lawrence Buell desde The Environmental Imagination (1995) hasta The Future of Environmental Criticism (2005), reconociendo también la influencia de varios textos anteriores de Rachel Carson (Silent Spring 1962) y Annette Kolodny The Lay of the Land (1975) entre otros valiosos, 66, 86 .

iii Similar al feminismo, el ecofeminismo tiene muchas ramas de interpretación teórica, involucrando lo constructivo, lo económico, lo espiritual, y lo biológico es su estudio.

La interconexión entre la naturaleza biológica de la mujer y la tierra es el eje del temprano ecofeminismo esencialista (Radford Ruether, Daly, la temprana Shiva) mientras las teorías más recientes descartan el enlace natural por unos enlaces sociales como en el ecofeminismo constructivista (Maathai, Plumwood), espiritual (Gebara, Shiva) y económico (Agarwal) que equiparan las posiciones de hombre y mujer. El análisis ecofeminista revela que muchas mujeres luchan en contra de su asociación singular con la naturaleza por su poder reproductivo, siendo así explotadas, desvaloradas y degradadas igual que la naturaleza por la sociedad patriarcal. Éticamente, las espiritualidades ecofeministas en particular levantan preocupaciones sobre la naturaleza como temas feministas porque ayudan a entender la opresión, subordinación, y dominación de las mujeres. Exploran los roles del rito, sistemas simbólicos y valores como por ejemplo los valores de cuido, reciprocidad, confianza, amor, parentesco y comunidad en camino hacia la justicia social (Warren 2000: 1; 1993: 120).

iv Véase el estudio de Carolyn Merchant, The Death of Nature. Women, Ecology and the Scientific Revolution, para un análisis de la trayectoria desde la antigüedad de la imagen y las metáforas de la naturaleza que sostiene una visión entre enriquecedora y amenazadora.

'Daniela Melis, 2005: 115.

${ }^{6}$ La crítica social recalca una voz claramente orientada a rechazar el poder político, efímero y económico de los imperios aun en los años 40: "Yo conozco muchas familias de negritos, en Limón, que están viviendo a punta de cangrejos y bananos. Se abandonan las fincas y no hay trabajo por ninguna parte, ¿qué vamos a hacer? Los blancos tienen el chance del Pacífico, pero ¿nosotros?" (9); "Pero al poco tiempo la tierra se cansó de dar bananos y ya el cacao no significó nada para los yanquis" (Mamita Yunai 65-66).

7 "My goal here is to interpret the novel's narrative strategy in the light of the decolonial theory conceptualized by Walter Mignolo, who highlights that the (re)writing of history according to another logic, another language, and another thought pattern contributes to the decolonization of knowledge understood as a community of universal interests and cultural heritage" [Mi meta aquí es de

\section{(2) $\odot \Theta \odot$}

La Revista Estudios es editada por la Universidad de Costa Rica y se distribuye bajo una Licencia Creative Commons Atribución-NoComercial-Compartirlgual 3.0 Costa Rica. Para más información envíe un mensaje a revistaestudios.eeg@ucr.ac.cr. 
Especial: Naturaleza amena y naturaleza agreste en las letras hispánicas

interpretar la estrategia narrativa de la novela bajo la luz de la teoría descolonial conceptualizada por Walter Mignolo, quien destaca que la (re)escritura de la historia según otra lógica, otro lenguaje, y otro patrón conceptual contribuye a la descolonización del conocimiento entendido por la comunidad de intereses universales y herencia cultural] (Melis 2011, 251).

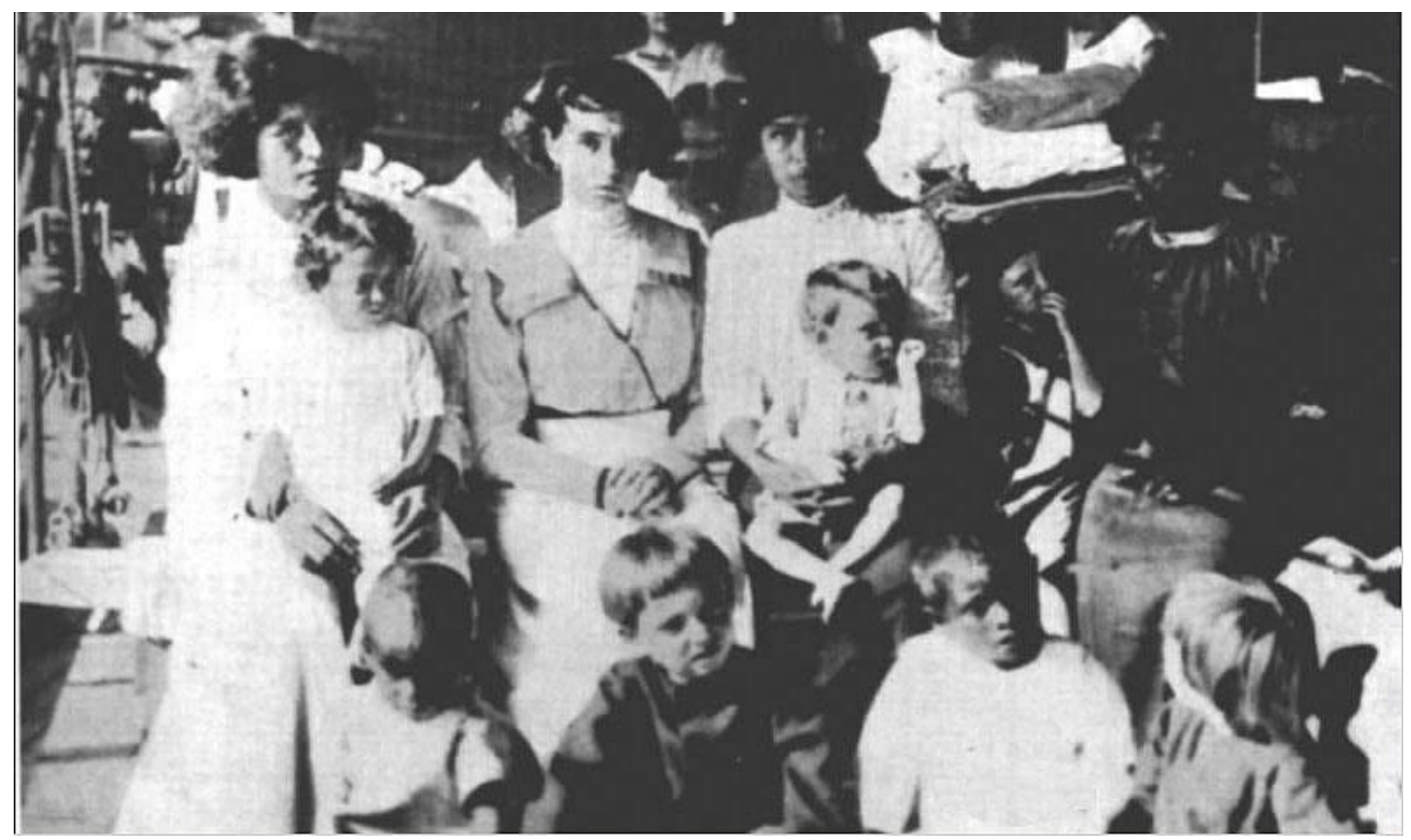

Los sobrevivientes al borde del barco Yorktown en su rescate, 1916.

\section{(C) $(\otimes \odot \odot$}

La Revista Estudios es editada por la Universidad de Costa Rica y se distribuye bajo una Licencia Creative Commons Atribución-NoComercial-Compartirlgual 3.0 Costa Rica. Para más información envíe un mensaje a revistaestudios.eeg@ucr.ac.cr. 